\title{
CRIMINOLOGIA: TRANSTORNOS NEUROPSÍQUICOS E IMPUTABILIDADE PENAL
}

\section{Vilson Aparecido Disposti ${ }^{1}$}

\section{RESUMO}

$\mathrm{O}$ artigo analisa a violação do princípio da culpabilidade, sustentáculo basilar do Direito Penal, que estruturado sob os demais princípios do Estado Democrático de Direito, deve projetar um Direito Penal mínimo e garantista. Entretanto, a proteção formal dos direitos e garantias individuais, no âmbito constitucional penal, não tem sido suficiente para se assegurar o jus libertatis do cidadão em conflito com o jus puniendi do Estado. A culpabilidade que fundamenta a aplicação da pena e limita a intervenção punitiva estatal, faculta ao magistrado individualizar a resposta penal de acordo com o necessário e o suficiente para a reprovação e a prevenção do crime. Porém, no Código Penal de 1940 encontram-se conceitos que não correspondem à realidade científica das psicopatologias identificadas e classificadas pela Criminologia moderna. Diferente da lei penal européia, o Código Penal brasileiro está aprisionado em seu hermetismo dogmático refletindo ainda, o reducionismo da Psiquiatria biofísica do século XIX. Esse isolamento inoculou na cultura jurídica criminal, acanhada visão das psicopatologias, que acrescido do mecanicismo da prática processual, afasta a justiça criminal de reconhecer os transtornos neuropsíquicos.É necessário que o Direito Penal brasileiro se abra à interdisciplinaridade da moderna Criminologia para adequar a sua resposta penal ao complexo fenômeno do crime.

Palavras-chave: Criminologia. Transtornos Psíquicos. Transtornos Neuropsíquicos. Toc-Transtorno obsessivo-compulsivo. Transtorno Bipolar, Transtorno da drogadição. Kleptomania. Imputabilidade. Culpabilidade. Medida de Segurança não detentiva.

\section{CRIMINOLOGY: NEUROPSYCHOSIS DISORDER AND PENAL IMPUTABILITY}

\footnotetext{
${ }^{1}$ Mestrado em Pós Graduação Stricto Sensu em Direito Proc. Penal pelo Centro Universitário Toledo, Delegado de Polícia do Secretaria de Segurança Pública do Estado de São Paulo,Brasil.E-mail: vilsondi@terra.com.br
} 


\begin{abstract}
This article examines the violation of the principle of culpability, "nulla poena sine culpa", basic cornerstone of criminal law, under which that structured under the other principles of the democratic state of law, shall project a minimum and guaranteed Criminal Law. However, the formal protection of rights and individual guarantees, in the constitutional-criminal, has not been sufficient to ensure the citizen "Jus Libertatis" against the State "Jus Puniendi". The culpability that justifies the imposition of sentences and limits the punitive intervention of the State provides the judge, to individualize the criminal response according to the necessary and the sufficient to the reprobation and prevention of crime. However, in the Criminal Code of 1940 are aimed, concepts do not match the reality of scientific psychopathology identified and classified by modern Criminology.Different the criminal codes of Europe, the Brazilian Penal Code remaining trapped in his hermeticism dogmatic, still reflecting the reductionism of the biophysical psychiatry of the nineteenth century. This isolates the legal culture of psychopathology cramped vision, plus the mechanism of procedural practice. This, prevent the criminal justice neuropsychosis to recognize the inconvenience.It is necessary for Brazilian Criminal Law is open to interdisciplinarity of modern Criminology to bring its criminal response to the complex phenomenon of crime.
\end{abstract}

KEYWORDS: Criminology. Mental disorders. Neuropsycho disorders. OCD-Obsessive-compulsive disorder. Bipolar disorder, disorder of drug addiction. Kleptomania. Imputability. Culpability. Security Measure non detentive.

\title{
INTRODUÇÃOO
}

$\mathrm{O}$ artigo analisa a violação do princípio da dignidade da pessoa humana, que constitui em um dos fundamentos da República Federativa do Brasil. Proclamado no artigo $1^{\circ}$, III da Constituição Federal, dele se extrai o dogma da culpabilidade, nulla poena sine culpa, sustentáculo do Direito Penal, que estruturado sob os demais princípios do Estado Democrático de Direito, deve projetar um Direito Penal mínimo e garantista.

Entretanto, a proteção formal dos direitos e garantias individuais, no âmbito constitucional, não tem sido suficiente para se assegurar o jus libertatis do cidadão em conflito com o jus puniendi do Estado.

A culpabilidade que fundamenta a aplicação da pena e limita a intervenção punitiva estatal, encontra-se positivada no artigo 59 do CP. Essa norma faculta ao magistrado, no momento de fixar a pena, o dever de atentar para a culpabilidade, a personalidade do agente 
e as demais circunstâncias do crime, para individualizar a resposta penal de acordo com o necessário, o suficiente para a reprovação e a prevenção do crime.

Porém, o Código Penal de 1940, sem conceituar a culpabilidade e a imputabilidade, preferiu relacionar as causas que a exclui ou diminui. No artigo 26 caput e parágrafo único, estão objetivados conceitos como "doença mental e perturbação da saúde mental”, cujas expressões, desde há muito, não correspondem à realidade das psicopatologias estudadas e classificadas pela Neuropsiquiatria. Enquanto a Criminologia vem possibilitando o exame do delito como fenômeno real, considerando-o como infração individual e acontecimento social, analisando o infrator em sua complexidade bio-psico-social (MOLINA; 2008).

Quanto às causas de exclusão e diminuição da imputabilidade penal, decorrentes das anomalias psíquicas ou neuropsíquicas, os códigos penais europeus, como o alemão, espanhol e português acolheram os preceitos da Criminologia moderna, adequando-se à nova ordem científica. Entretanto, o Código Penal brasileiro aprisionado em seu hermetismo dogmático, segue alheio à Criminologia. Por isso, reflete ainda os conhecimentos reducionistas e ultrapassados da Psiquiatria somática do século XIX, que se fundamentava apenas no organicismo biológico, deixando à margem o psiquismo humano.

O isolamento científico do Direito Penal pátrio tem inoculado na cultura jurídica brasileira, acanhada visão das psicopatologias que, acrescido ao mecanicismo da prática processual, tem levado os operadores da Justiça Criminal a não reconhecerem a semiimputabilidade decorrente de desordens neuropsíquicas.

Alguns transtornos da ansiedade se destacam por sua delictogênese como o TOCtranstorno obsessivo-compulsivo, transtorno bipolar, cleptomania, piromania, transtorno devido ao uso de substâncias psicotrópicas e outros. Embora tais anomalias não retirem a capacidade intelectiva do agente, afetam a autodeterminação, o que os coloca na zona fronteiriça entre os imputáveis e inimputáveis penalmente, portanto, semi-imputáveis.

O Código de Processo Penal, entre os artigos 149 e 154, disciplina o Incidente de Insanidade Mental. Porém, nem mesmo a defesa dele se vale para investigar a insanidade psíquica do acusado, a fim de lhe proporcionar justo tratamento jurídico. O reconhecimento da semi-imputabilidade, oriunda dos transtornos mencionados, possibilitaria ao juiz, no momento de aplicar a pena, substituí-la por medida de segurança não detentiva, consistente no tratamento médico especializado previsto no artigo 98 do CP. 
Para melhor compreensão do hermetismo do Direito Penal Brasileiro, no que diz respeito à subjetividade do agente, é interessante uma análise do Direito Penal alemão, espanhol e português. Este estudo comparativo demonstra a necessidade de o Direito Penal brasileiro abrir-se à interdisciplinaridade da Criminologia, bem como, coordenar ações de Política Criminal, para dar respostas mais adequadas ao complexo fenômeno do crime.

\section{A Imputabilidade Penal e a Criminologia}

A imputabilidade é pressuposto da culpabilidade, a qual se fundamenta na capacidade do autor de compreender a ilicitude do fato e determinar sua vontade, segundo essa compreensão. (WELZEL, 1997). ${ }^{2}$. Portanto, reprovável é o fato praticado pelo agente imputável que reúne condições pessoais para saber que a sua ação era proibida e que poderia ter agido de acordo com a lei. É o que a Doutrina denomina tecnicamente de potencial consciência da ilicitude e exigibilidade de conduta diversa.

Porém, ao tratar da imputabilidade o Código Penal, preferiu apresentá-la negativamente ao relacionar as causas que a exclui, como se vê a seguir, no caput do artigo 26 do CP:

É isento de pena o agente que, por "doença mental" ou desenvolvimento mental incompleto ou retardado, era, ao tempo da ação ou da omissão, inteiramente incapaz de entender o caráter ilícito do fato ou de determinar-se de acordo com esse entendimento. (BRASIL 2009, p.283).

O elemento subjetivo doença mental empregado no artigo em referência, corresponde às patologias orgânicas. Porém, tal expressão é extremamente limitante, considerando-se que a Criminologia integrada da Psiquiatria Criminal, não se ocupa apenas das enfermidades mentais de base biofísica, mas também daquelas caracterizadas puramente por reações comportamentais anormais, detectando que muitos infratores apresentam anomalias psíquicas mais importantes que as anatômicas para explicar a gênese do comportamento criminal. (CONDE, 2008).

No âmbito penal reconhece Reale Júnior (2002), que o termo “doença mental" revela-se a plena razão de não pretender o legislador referir às doenças mentais,

$2 \mathrm{O}$ autor assim define a imputabilidade: "Imputabilidad o capacidad de culpabilidad es, según ello, capacidad de comprender lo injusto del hecho, y de determinar la voluntad conforme a esta comprensión [...]La comprensión que la esencia da la culpabilidad reside en la "reprochabilidad" (en el "poder en lugar de ello" del autor en relación a su estructuración antijurídica de la voluntad) ha sido el resultado de un largo proceso de desarrollo". (WELZEL, 1997, p.182). 
considerando-se as variadas classificações apresentadas por psiquiatras como KURT SCHNEIDER FERRIO, BIONDI e outras que se acresceram ao longo dos anos.

Para o ordenamento penal pátrio (CP, art. 26) inimputável é o portador de doença mental, desenvolvimento mental incompleto ou retardado que o impede plenamente de compreender o caráter criminoso fato e agir segundo esse entendimento, enquanto os semiimputáveis são infratores vitimados pela "perturbação da saúde mental” em face de reduzida capacidade intelectiva e volitiva:

\begin{abstract}
A pena pode ser reduzida de um a dois terços, se o agente, em virtude de "perturbação de saúde mental" ou por desenvolvimento mental incompleto ou retardado não era inteiramente capaz de entender o caráter ilícito do fato ou de determinar-se de acordo com esse entendimento. (BRASIL, 2009, p.283)
\end{abstract}

A norma penal, ao se referir à perturbação da saúde mental revela um sentido de alteração do psiquismo humano diverso da doença mental de base puramente biológica. A perturbação da saúde mental converteu-se no conceito de psicopatia, utilizado pela Psiquiatria moderna para explicar todos os comportamentos anômalos que abrangem os transtornos psíquicos e neuropsíquicos que violam os padrões sociais e a lei penal. (CONDE, 2008).

O Código Penal, em seu artigo 18, considera crime doloso quando o agente quis o resultado ou assumiu o risco de produzi-lo. "Só a conduta baseada na vontade é penalmente relevante.”(MAURACH, 1994, p. 242). Para a doutrina penal, dolo é a vontade de agir, orientada para a realização do tipo de um delito. "Pelo que, toda ação consciente é conduzida pela decisão de agir, dividindo-se no momento intelectual e volitivo. A conjugação desses dois momentos configura uma ação típica real formando o dolo". (WELZEL, 1997, p. 77).

A síntese analítica da dogmática penal acerca da imputabilidade da conduta humana evidencia a polarização do Direito Penal na proteção do bem jurídico, enquanto a subjetividade do comportamento humano se encontra enclausurada na objetivação normativa do dolo. "O direito vigente só conhece uma individualização semelhante no nível da aplicação judicial da pena e não para a fundamentação da culpabilidade". (MAURACH, 1994, p. 517). No direito penal pátrio, essa individualização se dá apenas no momento da fixação da pena, prevista no artigo 59 do CP. 
A cultura tradicional, via regra, concebe o direito como instrumento de preservação e contenção social. Há que se despertar o potencial ético e transformador do fenômeno jurídico, cabendo aos operadores do direito introjetar e incorporar os seus valores inovadores. (PIOVESAN, 2008, p. 208).

Para o Direito Penal, ciência do dever ser, o delito tem natureza formal e normativa e por isso compreende apenas parcialmente a realidade, por meio de critério valorativo. Em razão disso, o jurista trata o fato criminoso como abstração, não de forma direta ou imediata, mas por meio da figura típica da norma. Embora, "os fins imediatos do Direito Penal seja a proteção de bens jurídicos do homem e da comunidade”. (DOTTI, 2002, p. 48).

Todavia, o Direito Penal não basta a si mesmo e para explicar a vontade humana, que é adotada como fundamento do dolo. Roxin destaca que: "O Direito Penal moderno, não pode ser refratário à contribuição das demais ciências, cujo saber interdisciplinar deveria integrar uma ciência global de Direito Penal”. (1997, p.47).

Nota-se que a doutrina penal de Roxin guarda estreita sintonia com a Criminologia que é a ciência do ser e se ocupa com a "imagem global do fato e do seu autor" (MOLINA, 2008, p. 68), qual seja, a etiologia do fato real, sua estrutura interna e dinâmica, formas de manifestação, técnicas de prevenção do mesmo e programas de intervenção no infrator.

A dogmática normativa penal marcada pelo seu isolamento científico implica na limitação de suas funções precípuas e resulta na ineficácia da aplicação da pena, na não prevenção ao crime e, principalmente, no desrespeito ao direito de liberdade.

Daí a importância que, para evitar a cegueira frente à realidade que muitas vezes tem a regulação jurídica o saber normativo, ou seja, o jurídico, deva ir sempre acompanhado, apoiado e ilustrado pelo saber empírico, isto é, pelo conhecimento da realidade informado pela Sociologia, Psicologia, Antropologia ou qualquer outra ciência, de caráter não jurídico, que se ocupe de estudar a realidade do comportamento humano em sociedade. (CONDE, 2008, p. 5).

Contrapondo-se à teoria do finalismo penal, Iris Oldano (1998) argumenta que as necessidades humanas se manifestam como desejos e tendências, motivam e regulam a atividade do homem, para o qual é necessário que conte com o objetivo que o impulsione em alguma direção e o motivo é o que lhe dirige a atuação, a fim de satisfazer uma necessidade. Mas, não se deve confundir finalidade delitiva como motivação criminal. Um mesmo motivo 
pode levar a atuar com fins distintos, o significado da ação é dado pelo motivo e não pela finalidade.

Desse modo, o ato de subtrair coisa alheia tem, para o Direito Penal, característica meramente patrimonial. No entanto, para a Criminologia, possui um significado muito mais amplo porque analisa o conteúdo biológico e psicológico da conduta, no contexto social e comunitário do problema. Nesse aspecto, ressalta Pablos de Molina:

Do mesmo modo que um diagnóstico psiquiátrico diferencial, a Criminologia obriga a distinguir (ainda que juridicamente se trate de infrações patrimoniais, em todos os casos) o furto que comete o ancião por razão de sua demência, do que comete o neurótico em uma crise de ansiedade ou o cleptomaníaco, porque não controla os seus impulsos ou o fetichista, por motivações sexuais, ou o oligofrênico, como conseqüência de seu retardo mental, ou o drogado, para financiar seu consumo, ou quem padece de um transtorno anti-social da personalidade, como conseqüência de sua psicopatologia ou uma psicose maníaca depressiva. O furto, em cada caso, tem um significado distinto. (2008, p. 68).

Para contextualizar a semi-imputabilidade, decorrente dos transtornos psíquicos e neuropsíquicos, foram examinados até aqui os preceitos da Ciência Penal e alguns fundamentos da Criminologia. Porém, para melhor compreensão do tema, se impõe a análise de algumas das psicopatologias que podem levar determinadas pessoas a romperem com os padrões sociais ou agirem contra o ordenamento penal.

\section{Transtornos de ansiedade e transtornos do comportamento}

Jung (apud PALMER, 1997), ensina que no indivíduo existem lutas internas, seja em torno de suas características pessoais que prefere ocultar valores que considera incompatíveis com sua personalidade pública, ou seja, como padrões emocionais ou comportamentais inconscientes masculinos ou femininos. É o que a psicanálise de Jung denomina de "individuação", alertando que se trata de um processo difícil, doloroso e, por vezes, perigoso, porque nesse caso pode ser autodestrutível.

Naturalmente, esse processo é permeado por conflitos e desejos que geram ansiedades de variáveis níveis. A ansiedade é um estado emocional com componentes psicológicos e fisiológicos, que faz parte do espectro normal das experiências humanas, sendo propulsora do desempenho. A ansiedade seqüestra o intelecto e passa a ser patológica quando é desproporcional à situação que a desencadeia, ou quando não existe um objeto 
específico ao qual se direcione. Os transtornos de ansiedade estão entre os transtornos psiquiátricos mais freqüentes na população. (GOLEMAN, 2001).

$\mathrm{Na}$ Classificação Estatística Internacional de Doenças e Problemas Relacionados à Saúde (MANUAL-CID-10, USP, 2006), alusiva à Psiquiatria e Neurologia relacionada com os transtornos vinculados à ansiedade, destacamos aqueles que podem impulsionar comportamentos incriminados, como: o Toc-Transtorno obsessivo compulsivo, Transtornos afetivo bipolar, Transtornos devidos ao uso de drogas, Transtornos dos hábitos e dos impulsos, que subdivide em cleptomania, piromania entre outros. Essas psicopatologias disparam intrincados mecanismos neuropsíquicos no indivíduo que podem levá-lo à realização de instintos e desejos reprimidos. A Neurociência defende que tais anomalias se devem ao desequilíbrio neurobioquímico.

\begin{abstract}
A angústia constitui o núcleo fundamental dos transtornos da ansiedade ou neuroses, (exceto nas neuroses obsessivas), a partir do qual emergem outros fenômenos psicopatológicos: irritabilidade, fobias inquietude, déficit de atenção e concentração. Nas neuroses obsessivas, a tristeza, o sentimento de culpa e a dúvida, prevalece como sentimentos nucleares do quadro. A personalidade do neurótico exibe alguns traços significativos. $\mathrm{O}$ neurótico tem um mau controle de sua vida instintiva, pelo que está submetido a uma luta impulsional que lhe acarreta penosas tensões internas. (MOLINA, 2008, p. 266).
\end{abstract}

\title{
TOC - Transtorno Obsessivo-Compulsivo
}

A Organização Mundial de Saúde-OMS, conceitua o TOC- Transtorno ObsessivoCompulsivo, como uma doença na qual o indivíduo apresenta obsessões e compulsões, ou seja, sofre de idéias e comportamentos que podem parecer absurdas ou ridículas para a própria pessoa e para os outros e que, mesmo assim, são incontroláveis, repetitivas e persistentes. A pessoa é dominada por pensamentos desagradáveis e obsessivos com conteúdo sexual e trágico, entre outros que podem ser aliviados temporariamente por determinados comportamentos.

O transtorno obsessivo-compulsivo - TOC abrange sintomas que representam diversos domínios psicopatológicos. Estes sintomas incluem percepções, cognições (obsessões), emoções, dificuldades nos relacionamentos sociais e diversos comportamentos motores (compulsões). As obsessões são caracterizadas por idéias, pensamentos, impulsos 
ou imagens intrusivas e inadequadas que causam acentuada ansiedade ou sofrimento. As compulsões, por sua vez, são comportamentos repetitivos ou atos mentais cujo objetivo é reduzir a ansiedade ou sofrimento, ao invés de oferecer prazer ou gratificação, como no caso dos comportamentos impulsivos. (FERRÃO, 2007).

O TOC, particularmente em suas formas mais graves, cursa com elevado grau de sofrimento psíquico e comprometimento psicossocial, por vezes comparável ao da esquizofrenia. (LOPES, 2004)

Ana Beatriz Barbosa Silva, médica psiquiátrica, especializada em Medicina do Comportamento, ressalta que o TOC, seria provocado pela combinação de diversos fatores como a predisposição genética, situações de estresse, fatores neurobioquímicos e psicológicos entre outros.

O transtorno obsessivo-compulsivo (TOC) constitui, com certeza, um dos quadros mais intrigantes e desafiadores da psiquiatria e psicologia atuais. Ele se caracteriza pela presença de obsessões e ou compulsões. As obsessões seriam pensamentos ou idéias recorrentes de caráter intrusivo e desagradável que causam muita ansiedade. As compulsões, conhecidas popularmente como "manias", são comportamentos, ações ou atitudes de aspecto repetitivo que a pessoa com TOC é levada a dotar em resposta a uma obsessão com o intuito de reduzir a ansiedade provocada por esta (BARBOSA, 2004, p. 23).

A Criminologia relaciona condutas impulsivas que tendem à violação das normas que tutelam a integridade corporal, liberdade sexual ou ainda delitos contra o patrimônio, como estelionatos e roubos. Os pacientes obsessivo-compulsivos sentem-se arrastados por uma força, pela sua inevitabilidade e pela impossibilidade de resistir aos sintomas, ainda que tentem. (DEL-PORTO, 2001). Nesse sentido, são significativos os fundamentos da Psiquiatria Criminal, como se pode observar:

\begin{abstract}
Os transtornos neuróticos geralmente crônicos representam uma percentagem elevadíssima do total dos transtornos psiquiátricos. Pesquisas mais recente sugerem a existência de bases biológicas anômalas que explicariam a particular sensibilidade ou vulnerabilidade dos neuróticos. Segundo se infere as pessoas com ansiedade, com obsessões ou quadros conversivos, teriam um sistema de alarme hiperativado. Sua angústia seria gerada por um desequilíbrio neurobioquímico. (MOLINA, 2008, p. 231).
\end{abstract}

Se os transtornos dos impulsivos caracterizam-se por incapacidade de resistir a um impulso, ou tentação de realizar algum ato que é prejudicial ao próprio indivíduo ou aos outros é compreensível que a repetitividade de comportamentos incriminados representa o 
deságüe do psiquismo sob tormenta, o que explica a reincidência criminal quando não tratados.

\title{
Transtornos no controle dos impulsos - Cleptomania
}

A cleptomania caracteriza-se por uma dificuldade recorrente para resistir aos impulsos de furtar objetos que não são necessários para o uso pessoal do agente ou pelo seu valor monetário. O agente experimenta uma sensação crescente de tensão antes da subtração seguida de bem estar e alívio ou liberação uma vez consumada a subtração. (MOLINA, 2008).

\begin{abstract}
Na cleptomania, a pessoa sente uma tensão crescente antes de cometer o furto e, no momento do ato em si, é tomada por uma sensação de prazer, alívio e gratificação. O cleptomaníaco não furta para acumular bens, tendo plena consciência de seus atos, porém sua vontade é engolfada pelos impulsos obsessivos ( BARBOSA, 2004, p. 94-5).
\end{abstract}

A Criminologia conclui que o agente não furta para acumular bens, tendo plena consciência de seus atos, porém, sua vontade é engolfada pelos impulsos obsessivos. Sobre esse transtorno é exemplar o episódio que culminou na prisão do rabino Henry Sobel que, segundo os médicos que o examinaram, padecia de transtorno de ansiedade e uma dependência psicotrópica derivada da automedicação. É o que ele próprio relata em seu livro Um homem. Um Rabino.

Decidi dar uma volta em Palm Beach. Estacionei o carro junto ao centro comercial e fui olhar as lojas. Era meu último dia por lá e pensei em, talvez, comprar algo para Alisha ou para Amanda...Lembro-me que entrei em uma loja, saí...entrei na segunda e não me recordo de mais nada. Apenas de uma policial de bicicleta, que me abordou depois na avenida. A gravação da câmera de segurança, que mais tarde foi exibida na TV, revelou que eu apanhei quatro gravatas sobre o mostrador, pus no bolso e saí andando em direção ao carro. No total, as gravatas custavam perto de setecentos dólares, bem menos do que eu tinha comigo, três mil dólares [...]. Eles ouviram a minha história, e concluíram que eu tinha um problema de saúde; não um problema moral ou ético. Eu não era um ladrão de gravatas. Fui convencido, então, a ir até o Hospital Albert Einstein. Lá, fomos recebidos por um grupo de médicos, incluindo o presidente do hospital, Cláudio Lottemberg. O grupo convocou o neurologista Fernando Huck. E a decisão dos médicos foi taxativa: eu deveria me internar para desintoxicação (SOBEL, 2008, p. 232-37). 
O transtorno do impulso, além da cleptomania, distingue também a ludopatia e a piromania que frequentemente levam o indivíduo ao conflito com o ordenamento penal.

\section{Transtorno afetivo bipolar}

O transtorno bipolar (TB) é uma doença crônica, recorrente e freqüente, que, além de potencialmente letal, pode ser tratada, mas não curada. Trata-se de uma patologia psiquiátrica complexa que envolve aspectos biológicos, psicológicos e sociais que se caracterizam por cursar com uma variabilidade de sintomas, elevada taxa de comorbidade com abuso ou dependência de substâncias, transtorno de ansiedade e outras doenças psiquiátricas e médicas sistêmicas. (MORENO, 2008).

Durante a fase maníaca do Transtorno bipolar, há euforia e irritabilidade, com manifestações de raiva, sentimento de pânico e desesperança; quanto à cognição, num estágio mais avançado, o pensamento é incoerente, com perda das associações, delírios bizarros e idiossincráticos, idéias de auto-referência, alucinações e desorientação temporoespacial; enquanto o comportamento é afetado por atividade psicomotora frenética e frequentemente bizarra. (HUPFELD MORENO, 2008, p. 158).

As disfunções na fisiologia levam às alterações comportamentais, como distúrbios de psicomotricidade, do impulso, dos ritmos biológicos, dos sistemas neuroendócrinos, além dos episódios do humor, dependência de drogas, suicídio e o comprometimento cognitivo. (MINATOGAWA; TUNG, apud MORENO, 2008).

No transtorno bipolar, a propensão criminógena se apresenta na fase maníaca, a qual como visto, caracteriza-se pela sintomatologia de euforia, irritabilidade, exaltação, incremento da atividade social, laboral, sexual, grande fluidez do pensamento, fuga de idéias, loquacidade, sentimentos de grandeza, evidente auto estima, predisposição para empreender negócios de risco, atividades perigosas, gastos desmedidos, hiperatividade psicomotora. (MOLINA, 2008).

\section{Transtorno devido ao uso de drogas}

A OMS denomina todos os quadros relativos ao consumo de drogas de "Transtornos mentais e do comportamento devido ao uso de substâncias psicotrópicas”. Trata-se de comportamentos compulsivos e aditivos adotados em função de alguma gratificação 
emocional, como o alívio do desconforto psíquico causado por ansiedade ou angústia, o que leva à repetição da mesma conduta.

São relevantes os fatores hereditários como causa de dependências químicas, portanto, se deve falar, em nome do rigor lingüístico, de genética das condições de vulnerabilidade ou suscetibilidade. Os trajetos para a gênese do abuso ou dependência de álcool e outras drogas são múltiplos, compreendendo caminhos específicos para cada droga e outros gerais para todas as drogas: possivelmente os casos individuais sejam misturas, em variadas proporções. Além de trajetos gerais e específicos para a transmissão hereditária da vulnerabilidade ao abuso ou dependência de drogas, coexistem suscetibilidades comuns a diversos fenótipos da psiquiatria; em alguns casos, não é possível rejeitar a hipótese da transmissão de traço comum a todos os transtornos psiquiátricos. (MESSAS; VALLADA FILHO, 2009).

Como visto, os fatores genéticos surgem como prevalentes, como causa dos transtornos da dependência de drogas. Segundo Cabrera Fornero (apud MOLINA, 2008), à delictogênese induzida ou associada à droga, leva o individuo à criminalidade instrumental que se constitui das ações para a obtenção e o financiamento da droga. Essa delinquência instrumental é representada por um conjunto heterogêneo de crimes praticados pelo dependente químico, para a compra das drogas, como furtos, roubos, estelionatos, falsificações de receitas e outros.

O legislador, ao descrever o crime de porte de substancias entorpecentes para o consumo pessoal, na nova Lei Antidrogas 11.343, de 23 de agosto de 2006, em seu artigo 28, revelou-se sensível à gênese psicopatológica dessa conduta, que a Criminologia, tem demonstrado cientificamente.

Acertadamente, a lei penal, dá adequada resposta ao usuário de drogas, ao não lhe impor pena privativa de liberdade, prevendo somente a aplicação de: "advertência sobre os efeitos das drogas; prestação de serviços à comunidade ou medida educativa de comparecimento a programa ou curso educativo". Entretanto, para o Direito Penal, crime é a infração penal punida com reclusão ou detenção, quer isolada ou cumulativa quer alternativamente com multa. Em razão disso, o artigo 28 é tecnicamente anômalo, porque é o único "crime" no Direito Penal pátrio, ao qual não se impõe pena privativa de liberdade. O Direito Penal se alinhado à Criminologia, bem poderia ter evitado esse imbróglio jurídico, se a dependência de drogas fosse tratada pela nova lei, sob a ótica da "semi-imputabilidade 
penal, decorrente do transtorno devido ao consumo de substâncias psicotrópicas" como demonstra a Criminologia, porque tais medidas poderiam ser adotadas em face do artigo 98 do Código Penal.

\section{Individualização da Culpabilidade}

Se o pressuposto da culpabilidade é a imputabilidade, cujo elemento fundamental é a livre vontade, então a conduta incriminada decorrente de anomalia psíquica ou neuropsíquica, seguramente, não poderia ser considerada ação livre. A culpabilidade, nesses casos, merece a análise da Justiça Criminal, sob a ótica dos fundamentos científicos da Criminologia, para a garantia do jus libertatis proclamado na Constituição Federal, como direito fundamental da República e ensejar mínima visibilidade à cifra negra constituída por esse grupo de pessoas.

O Código Penal, embora arcaico e hermético, prevê importante solução para os casos de semi-imputabilidade no artigo 98 como visto. Considerando que essa norma faculta ao juiz, a substituição da pena privativa de liberdade por medida de segurança não detentiva equivalente ao tratamento clínico.

“O Estado Moderno e o seu característico "monopólio da violência física”, legitimase pela legalidade, fazendo com que o seu poder de castigar também encontre na legalidade a sua legitimação" (SANCHES, 2006, p. 149).

Como se vê, não há óbices técnicos para se reconhecer condutas perturbadas por desordens neuropsíquicas que violam a lei penal. Porém, os fatores impeditivos remetem para o fenômeno do etiquetamento ${ }^{3}$ ou controle social, que ainda hoje, fomenta o estereótipo do louco medieval na cultura popular, que lamentavelmente transcende para a cultura jurídica brasileira.

Esse grupo de infratores comportados, por fugir ao estereótipo da excentricidade comportamental, acaba despercebido pelo mecanicismo processual e é considerado imputável. Punindo-os com a pena privativa de liberdade a conduta psicopatológica que venha encontrar correlação com uma norma penal, o que basta ao Direito Penal para classificá-lo como fato típico e antijurídico. Enquanto a causa que motivou a conduta, segue

\footnotetext{
${ }^{3}$ Teoria da Sociologia Criminal, que se refere ao labelling aproach traduzida por etiquetamento, rotulação ou reação social, defendida por Howard Becker e Erving Goffman, no sentido de que os grupos sociais criam os desvios, ao fazerem as regras cuja infração constitui o desvio e ao aplicarem tais regras a certas pessoas em particular, qualificam-nas como criminosas.
} 
sem identificação e ignorada pela Justiça Criminal, em razão do descompasso com a Criminologia. Nesses casos, geralmente, o próprio infrator também desconhece a gênese de sua habitualidade criminal que, resignado aceitou o estereótipo de criminoso. Assim, uma reposta penal inadequada agravará a sua psicopatologia, porque segue sem o tratamento médico especializado.

No Direito Penal, a tarefa da Criminologia é reduzida à explicação causal do comportamento criminoso, baseada na dupla hipótese do caráter complementar determinado do comportamento criminoso e da diferença fundamental entre os indivíduos criminosos e não criminosos (BARATTA, 1993. p. 43).

Se no processo penal, quanto às provas de autoria e materialidade do fato, o princípio objetivo da verdade real é imperativo, porque a verdade real subjetiva do infrator não deveria ser igualmente observada? O Direito Penal ao manter sua fixação na tutela do bem jurídico e na ordem pública, leva à responsabilidade penal objetiva, o que é inaceitável no Estado de Direito hodierno. "Se uma justiça penal completamente com verdade constitui uma utopia, uma justiça penal completamente sem verdade equivale a um sistema de arbitrariedade". (FERRAJOLI, 2006, p. 282).

"No tratamento das causas de exclusão de culpabilidade, existem marcantes exemplos desta orientação que conduz à responsabilidade objetiva, como a doença mental e o distúrbio de consciência" (DOTTI, 2002, p.81).

O Tribunal Constitucional Federal alemão declara que o princípio da culpabilidade deriva não só dos princípios gerais do Estado de Direito material, senão ademais especificamente da obrigação de se respeitar à dignidade humana. Dicho brevemente: la prohibición de vulnerar la dignidad debe limitar la optimización de la utilidad de la pena ${ }^{4}$ (JAKOBS, 1996, p. 16).

\section{A Criminologia no Direito Penal Europeu}

As legislações penais estrangeiras vêm reformulando a positivação de antigos conceitos ao adotar novos preceitos da Criminologia, adequando-se, portanto, à nova ordem científica. No bojo das transformações sócio-econômicas dos países da Europa, na razão direta em que as fronteiras econômicas e políticas se apagam, as legislações dos países membros tendem a se equalizar. Nesse contexto, vêm promovendo o ajuste da lei penal de

\footnotetext{
${ }^{4}$ El Tribunal Constitucional Federal alemán deriva el pricinpio de culpabilidad no solo de los principios generales del Estado de Derecho material, sino además específicamente de la obligación de respetar la dignidad humana. Dicho brevemente: la prohibición de vulnerar la dignidade debe limitar la optimización de la utilidad de la pena. (Tradução livre).
} 
forma a garantir a efetividade dos direitos fundamentais do homem, abraçados pela maioria dessas nações.

Ao sopro dessas transformações, foram atualizados os Códigos Penais de Portugal, Espanha e Alemanha. Veja-se a seguir, o que tais legislações dispõem sobre a o tema analisado nesse artigo.

O Código Penal lusitano, atualizado em 1995, em seu artigo $20^{\circ}$ determina:

É inimputável quem, por força de uma anomalia psíquica, for incapaz, no momento da prática do facto, de avaliar a ilicitude deste ou de se determinar de acordo com essa avaliação. (DOTTI, 2002, p.412).

A Exposição de Motivos da Lei Orgânica número 10/1995, que se constitui no Código Penal espanhol, salienta que a Lei Penal deve tutelar os valores e os princípios básicos da convivência social e quando esses valores e princípios se modificam, a lei deve ser igualmente modificada. (PARLAMENTO ESPANHOL, 2009) ${ }^{5}$

O Direito Penal espanhol avança, um pouco mais ao dispor em seu artigo 20 que estão isentos de responsabilidade criminal, aquele que ao tempo de cometer a infração, em decorrência de "qualquer anomalia ou alteração psíquica, não pode compreender a ilicitude do fato ou atuar em conformidade com essa compreensão". 6

A inovação mais expressiva ainda, encontra-se no Código Penal alemão de 1871, reformado em 31.01.1998, dispondo no artigo 122: "Não será penalmente responsável quem no momento da ação dos fatos, padeça de um transtorno psíquico ou neuropsíquico que haja anulado seu discernimento ou o controle de seus atos" (ALEMANHA, Código penal, 1998). ${ }^{7}$

\footnotetext{
${ }^{5}$ El Código Penal ha de tutelar los valores y principios básicos de la convivencia social. Cuando esos valores y principios cambian, debe también cambiar. En nuestro país, sin embargo, pese a las profundas modificaciones de orden social, económico y político, el texto vigente data, en lo que pudiera considerarse su núcleo básico, del pasado siglo. La necesidad de su reforma no puede, pues, discutirse. Se ha dado especial relieve a la tutela de los derechos fundamentales y se ha procurado diseñar con especial mesura el recurso al instrumento punitivo allí donde está en juego el ejercicio de cualquiera de ellos. (tradução livre)

${ }^{6}$ Ley Organica 10/1995 - El Codigo Penal de España - Artículo - 20 Están exentos de responsabilidad criminal: $1 .^{\circ}$ El que al tiempo de cometer la infracción penal, a causa de cualquier anomalía o alteración psíquica, no pueda comprender la ilicitud del hecho o actuar conforme a esa comprensión. (Tradução livre)

${ }^{7}$ Codigo Penal Alemán de 1871, con la última reforma del 31 de enero de 1998, traduccido por Claudia López Diaz: Artículo 122-1:

No será penalmente responsable quien, en el momento de la comisión de los hechos, padezca un trastorno psíquico o neuropsíquico que haya anulado su discernimiento o el control de sus actos. Quien esté aquejado, en el momento de los hechos, de un trastorno psíquico o neuropsíquico que haya alterado su discernimiento o dificultado el control de sus actos seguirá siendo punible; sin embargo, el órgano jurisdiccional tendrá en cuenta esta circunstancia cuando determine la pena y fije el régimen de la misma.
} 
É de se observar que a notável evolução do Direito Penal germânico, ao admitir os transtornos psíquicos e neuropsíquicos que retiram ou diminuem a capacidade de entender e querer do infrator, se liberou das limitações puramente organicistas da Psiquiatria biofísica. A esse respeito, veja-se a importante lição de Manuel da Costa Pinto:

A psiquiatria de hoje não é a mesma à qual $\operatorname{Lacan}^{8}$ se referiu. A tendência da psiquiatria atual chamada de biológica se caracteriza por ter seus fundamentos determinados por outras disciplinas científicas, principalmente a neurobiologia. Este novo modelo da psiquiatria critica os anteriores em seus métodos e os substitui por critérios estatísticos, excluindo os acontecimentos particulares da vida do sujeito na causação de seus transtornos (2007, pág. 352).

No Brasil, a Política Criminal é destituída de qualquer coordenação, razão pela qual, o Direito Penal é assinalado apenas por transformações pontuais para atender à demanda da expansão do Direito Penal, com a criminalização de novas condutas, que em regra, não encontra resistência social e política. Enquanto isso, os temas mais complexos são deixados à margem, como este que aqui relacionamos. Nem por isso, se deve descurar que o comportamento humano, objeto fundamental do Direito Penal, merece ser considerado sob os postulados científicos da Criminologia. As ciências psi fruem de um momento auspicioso cientificamente, considerando-se a integração se seus conhecimentos sobre o fenômeno humano, portanto, é incompreensível a relutância do Direito Penal brasileiro, em abrir-se à Criminologia.

Faz se necessário à cultura jurídica tradicional aprimorar o conhecimento do Direito Internacional Público, em particular do Direito Internacional dos Direitos Humanos. Há que se romper a distancia e o divórcio entre o Direito Internacional e o Direito Interno, notadamente quando se trata de direitos fundamentais. (PIOVESAN, 1999, p. 208)

A integração do Direito Penal inglês com a Psiquiatria proporciona um trabalho de melhor qualidade. Tal fato foi destaque na Revista Brasileira de Psiquiatria de outubro de 2003, como segue:

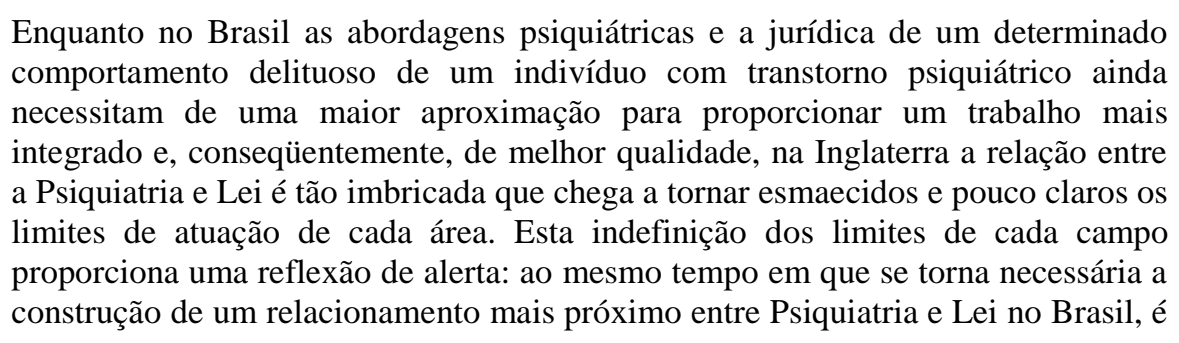

\footnotetext{
${ }^{8}$ Jcques Marie Émile Lacan, 1901-1981- médico e psicanalista francês, fundador da Escola Freudiana de Paris EFP e Escola da Causa Freudina ambas em Paris.
} 
igualmente importante ter clareza do alcance e, conseqüentemente, do limite de cada uma das abordagens. (ABDALLA-FILHO; ENGELHARDT, 2003, vol. 25, 4)

\section{Violação da dignidade humana e da ampla defesa do acusado}

O Código Processual Penal, artigo 149, preceitua que o "incidente de insanidade mental do acusado" possa ser determinado de ofício pelo juiz, ou requerido pelo Ministério Público, defensor, curador, ascendente, descendente, irmão ou cônjuge do acusado. No entanto na prática processual, somente ele é argüido quando o réu apresenta ostenta claras evidências de sua piscopatologia, como já relacionado.

A ausência dessa percepção tem inibido a instauração deste "incidente", cuja ausência corresponde à franca exclusão de um direito ao acesso à ordem jurídica justa e, conseqüentemente afronta ao direito de ampla defesa e à dignidade da pessoa humana, para o triunfo da responsabilidade penal objetiva.

\footnotetext{
Se o substancialismo jurídico e o formalismo ético convergem desde o ponto de vista externo na deformação científica e na atribuição ideológica de valor ao direito penal vigente, as orientações substancialistas apresentam, desde o ponto de vista jurídico ou interno, o defeito último de conflitar com o princípio da estrita legalidade e de serem acordes com os sistemas autoritários de direto penal máximo. (FERRAJOLI, 2006, p. 345).
}

O reconhecimento judicial da semi-imputabilidade, associado ao princípio da finalidade da pena, levaria o juiz a aplicar a medida de segurança não detentiva, ou seja, remeteria o réu ao tratamento seu transtorno psíquico, em vez introduzi-lo no sistema penal.

É de se observar que, o acusado torturado psiquicamente por transtornos neuropsíquicos não detectados durante o processo, será considerado imputável, portanto, conduzido ao cárcere, se não fizer jus às penas substitutivas. Como já mencionado, nem sempre o infrator tem consciência de que seu comportamento é motivado por uma psicopatologia, o que lhe agravará a situação.

Marchewka (2003), ao discorrer sobre a questão do aprisionamento do juiz frente aos laudos psiquiátricos, coloca o direito penal no plano que afeta as garantias do homem: $\mathrm{O}$ verdadeiro criminoso seria conduzido à prática delituosa por causas biopsíquicas e, como consequiência desse determinismo criminológico a solução lógica seria buscar o seu tratamento, se possível preventivo e não seu castigo. 
Nesse ponto, encontra-se a área de conflito entre o jus puniendi estatal, que instrumentalizado pelo Direito Penal, viola o jus libertatis do cidadão. "O princípio da dignidade humana incide diretamente sobre todas essas situações dramáticas, normalmente em tensão com o direito à liberdade e à vida biológica". (VILHENA, 2006, p. 69). Igualmente, assinala ALEXY (2008, p. 94-5), que há “uma relação de tensão entre o dever estatal de garantir uma aplicação adequada do direito penal e o interesse do acusado na garantia de seus direitos constitucionalmente consagrados, para cuja proteção a Constituição também obriga o Estado".

Portanto, cumpre ao Estado Democrático de Direito velar efetivamente pelo respeito aos direitos individuais, notadamente a dignidade da pessoa humana, atentando-se para os princípios de um Direito Penal "garantista”. O garantismo, no Direito Penal é apresentado por Luigi Ferrajoli (2006), em defesa da efetivação do devido processo legal, como garantias das partes, essencialmente do acusado e como garantias do justo processo.

\section{Considerações Finais}

O Direito Penal ao emergir do Direito Público apresenta-se, no contexto do ordenamento jurídico, como instrumento do poder repressor do Estado, visando à tutela de bens jurídicos, a segurança de seus cidadãos e a preservação do próprio Estado, atento à manutenção da ordem pública via controle social.

Nesse contexto, o Positivismo Jurídico e o Liberalismo que marcam acentuadamente o Direito Penal brasileiro, impõem na Justiça Criminal resignada e cômoda cultura que segue refém do cientificismo e normativismo jurídicos, que o isolam da realidade social e dos anseios de justiça. Esse fenômeno tolhe a liberdade do julgador de decidir com equidade, sejam decisões condenatórias ou absolutórias, o que produz enorme frustração na sociedade por não compreender a reinante dicotomia entre o "justo" e o "legal" nos reiterados julgamentos que ferem a razoabilidade e o bom senso do cidadão mediano.

A entrega da prestação jurisdicional penal, que culmina com a sentença, é um momento em que o juiz, via de regra, se dá por satisfeito por ter aplicado a lei penal. Na cultura jurídico-penal brasileira blindada pela dogmática-penal, o julgador é dotado de um automatismo funcional da Justiça Criminal e significativo utilitarismo na preservação da ordem jurídica, dispensado que está de preocupar-se com a justiça. Se a decisão é legal é justa, ainda que não o seja. É a Lei! 
A Justiça Criminal necessita adotar por meta política e social, o compromisso de velar pela garantia constitucional de acesso efetivo à Justiça, exigindo do intérprete e aplicador das normas do processo a atenção necessária e compatível com o sentido de ordem pública predominante, em tudo que diga respeito ao conflito entre o jus puniendi e o jus libertatis.

O Positivismo ora em crise, para não fugir ao controle científico que visa resguardar a Ciência do Direito, cuidou de objetivar até mesmo o que não é passível de objetivação. O dolo foi positivado como "vontade livre e consciente" de se produzir um resultado lesivo ao bem jurídico, base em que repousa a reprovabilidade do Estado, sobre o agente que assim agiu.

O que se desejou evidenciar, nessa pesquisa, foi a indiferença sistemática com que a Justiça Criminal brasileira trata a subjetividade do agente, especialmente dos semiimputáveis, porque invisíveis.

Se a culpabilidade penal que recai sobre a conduta incriminada, encontra-se fundamentada na livre vontade humana e se as incidências dos transtornos psíquicos e neuropsíquicos recaem sobre a vontade do agente, essas anomalias do psiquismo merecem a consideração jurídico-penal. Posto que, a liberdade de ação não é plena, porque comprometida por perturbações que a depender de seu grau, o infrator não age, é atuado. Por isso, é indubitável o reconhecimento pela Justiça Criminal, da relevância da gênese criminógena dessas condutas. Portanto, é inadiável, a revisão e flexibilização, para que a função jurisdicional penal, como instrumental do direito material, não seja algoz dos diretos individuais e óbice ao acesso processo justo.

As ciências humanas projetam e dinamizam o saber sobre a realidade do ser e sua correlação com o meio social em que vive para melhor compreender a complexidade do ser humano.

A Criminologia estuda o fenômeno do crime, o psiquismo do criminoso e o contexto social em que o fenômeno do delito se manifesta, valendo-se da integração da Sociologia Criminal, Psicologia Criminal e Psiquiatria Criminal e demais ciências afins, como a Neurobiologia e a Psicanálise.

A conjunção dessas ciências revela e existência de um homem integral, por examinálo em sua dualidade física e psíquica, como realidade única. Assim, se faz necessário ampliar o alcance das teorias do Direito Penal em consonância com as outras ciências do 
homem e dar ao julgador a liberdade de decidir equitativamente já que auxiliado pelos peritos na análise fisiopsíquica do homem.

É imperioso o alinhamento do Direito Penal pátrio às bases científicas da Criminologia e ciências afins, como já o fizeram a maioria dos países comprometidos com a consolidação do Estado Democrático de Direito, em defesa dos Diretos Humanos, de que são exemplos as nações da Europa continental.

É indubitável, que se no processo penal vigora o princípio da verdade real, quanto à existência do crime e a prova de sua autoria, porque em jogo o direito à liberdade e os demais princípios que dele emergem. Pelo que, maior será a justificativa para se demandar à verdade real da pessoa humana, cuja conduta é conflitante com a lei penal. 


\section{REFERÊNCIAS}

ABDALLA FILHO, Elias; ENGELHARDT, Wolfram. A prática da psiquiatria forense na Inglaterra e no Brasil: uma breve comparação Revista Brasileira de Psiquiatria. V. vol. 25, n. 4, São Paulo, out. 2003.

ALEXY, Robert. Teorias dos Direitos Fundamentais. São Paulo: Mallheiros Editores, 2008.

BARATTA, Alessandro. Criminologia crítica e crítica do direito penal. Rio de Janeiro: Revan, 1993.

BRASIL. Código Penal, 5a ed. São Paulo: Saraiva, 2009.

BRASIL. Código Processual Penal, 5ª ed. São Paulo: Saraiva, 2009.

BRASIL. Constituição (1988). Constituição [da] Republica Federativa do Brasil. Brasília: Senado Federal, 2006.

BRASIL. Lei 11.343, de 23 de Agosto de 2006. Institui o Sistema Nacional de Políticas Públicas sobre Drogas, $5^{\text {a }}$ ed. São Paulo: Saraiva, 2009

CÓDIGO. penal Alemán. Trad. Claudia Lopes Diaz, Universidad Externado de Colombia, Bogotá,1999. Disponível em: <http://www.unifr.ch/ddp1/derechopenal/obras/stgb.pdf>. Acesso em: 25 ago. 2008.

CÓODIGO penal. Ley organica 10/1995, de 23 de noviembre, del CODIGO PENAL, Madrid, 23 Nov. 1995. Disponível em: <http://www.derecho.com/l/boe/ley-organica-10-1995-codigopenal/ > Acesso em: 24 ago. 2008.

DEL PORTO, Alberto. Epidemiologia e aspectos transculturais do transtorno obsessivocompulsivo. Revista Brasileira de Psiquiatria, 2004, n. 26, p.62-6.

DOTTI, René Ariel. Curso de direito penal: parte geral, Rio de Janeiro: Forense, 2001.

FERRARI, Eduardo Reale. Medidas de segurança e direito penal no estado democrático de direito. São Paulo: Revista dos Tribunais, 2001.

FERRAJOLI, Luigi. Direito e razão: teoria do garantismo penal. 2. ed. São Paulo: Revista dos Tribunais, 2006.

CONDE, Francisco Munhoz; HASSEMER, Winfried. Introdução à Criminologia. Rio de Janeiro: Lumen Juris, 2008.

FERRÃO, Ygor Arzeno. Revista Brasileira de Psiquiatria.2007. Disponível em: <http://www.scielo.br/pdf/rbp/v29s2/art5.pdf>. Acesso em: 18 abr. 2009 
FOUCAULT, Michel. Problematização do sujeito: psicologia, psiquiatria e psicanálise. Rio de Janeiro: Forense Universitária, 1999.

GOLEMAN, Daniel. Inteligência emocional. Rio de Janeiro: Objetiva, 2001.

JAKOBS, Günther. Fundamentos del derecho penal. Buenos Aires: LAF; 1996.

OLDANO, Iris. Criminilogia Agressividade y Delincuencia. Buenos Aires: Ad Hoc, 1998.

MARCHEWKA, T. M. N. As contradições das medidas de segurança no contexto do direito penal e da reforma psiquiátrica no Brasil. Revista de Direito UPIS, Brasília: n.1, 97-111, jan. 2003. Disponível em: <http://www.upis.br/revistadireito/rev_dir_vol1.pdf\#page=97> Acesso em: 26 set. 2008.

MAURACH, Reinhart. Derecho PenaL. Buenos Aires: Editorial Astrea, 1994.

PALMER, Michael. Freud e Jung. São Paulo, Editora: Loyola, 2001.

MOLINA, Antonio García-Pablos; Luiz Flávio Gomes. Criminologia. 6. ed. São Paulo: Revista dos Tribunais, 2008.

MORENO, Ricardo Alberto; HUPFELD, Dóris (orgs.). Da Psicose Maníaco-Depressiva ao Espectro Bipolar. 3. ed. São Paulo: Segmento Fama, 2008.

PINTO, Manuel Costa. Psicanálise: o pensamento de Freud, Jung, Melaine Klein, Lacan, Winnicott e outros. Rio de Janeiro: Ediouro, 2007.

PIOVESAN, Flávia. Direito Global. São Paulo: Max Limonad, 1999.

REALE-JÚNIOR, Miguel. Instituições de Direito Penal. Rio de Janeiro: Forense, 2002.

ROXIN, Claus. Derecho Penal. Parte General Tomo I. Fundamentos: La Estructura de la teoria del delito. Madrid: Editorial Civitas, 1997.

SANCHES, Samyra Haydêe Dal Farra Naspolini. O sistema penal como objeto de estudo da criminologia crítica. Revista de mestrado em Direito do Centro Universitário Toledo de Araçatuba, Araçatuba, v. 6, n. 1, p. 146-171, 2006.

SILVA, Ana Beatriz Barbosa. Mentes inquietas. 34. ed. São Paulo: Gente, 2003.

Mentes \& manias. 2. ed. São Paulo: Gente, 2004.

SOBEL, Henry I. Um homem. Um rabino. Rio de Janeiro: Ediouro, 2008.

VIEIRA, Oscar Vilhena. Direitos Fundamentais. São Paulo: Malheiros Editores, 2006.

WELZEL, Hans. Derecho Penal Alemán. Parte General. 4. ed. Santiago de Chile: Editorial Jurídica de Chile, 1997. 